\title{
Degradation of carboxy-terminal-tagged cytoplasmic proteins by the Escherichia coli protease HfiB (FtsH)
}

\author{
Christophe Herman, ${ }^{1,4,5}$ Danielle Thévenet, ${ }^{2}$ Philippe Bouloc, ${ }^{3}$ Graham C. Walker, ${ }^{4}$ \\ and Richard D'Ari ${ }^{2}$ \\ ${ }^{1}$ U niversité Libre de Bruxelles, B-1640 Rhode-Saint-Genèse, Bel gium; ${ }^{2}$ Institut Jacques M onod [Centre $\mathrm{N}$ ational \\ de la Recherche Scientifique (CN RS), Université Paris 6, U niversité Paris7], F-75251 Paris Cedex 05, France; ${ }^{3}$ Institut \\ de Génétique et Microbiologie (Université Paris-Sud, CN RS), F-91405 Orsay Cedex, France; ${ }^{4}$ Department of Biology, \\ Massachusetts Institute of Technology, Cambridge, M assachusetts 02139 USA
}

\begin{abstract}
Proteins with short nonpolar carboxyl termini are unstable in Escherichia coli. This proteolytic pathway is used to dispose of polypeptides synthesized from truncated mRNA molecules. Such proteins are tagged with an 11-amino-acid nonpolar destabilizing tail via a mechanism involving the 10Sa (SsrA) stable RNA and then degraded. We show here that the ATP-dependent zinc protease HflB (FtsH) is involved in the degradation of four unstable derivatives of the amino-terminal domain of the $\lambda \mathrm{Cl}$ repressor: three with nonpolar pentapeptide tails (cl 104, cl 105, cl 108) and one with the SsrA tag (cl-SsrA). cl 105 and cl-SsrA are al so degraded by the ClpP-dependent proteeses. Loss of ClpP can be compensated for by overproducing HflB. In an in vitro system, cl108 and cl-SsrA are degraded by $\mathrm{HflB}$ in an energy-dependent reaction, indicating that HflB itself recognizes the carboxyl terminus. These results establish a tail-specific pathway for removing abnormal cytoplasmic proteins via the HflB and Clp proteases.
\end{abstract}

[Key Words: 10Sa RNA; AAA ATPase family; intracellular proteolysis; tail-specific proteolysis; CIp protease; proteasome 26S]

Received February 6, 1998; revised version accepted March 12, 1998.

Living cells have elaborate mechanisms such as check points and coupling devices to evaluate their physiological state and environment to mai ntain a harmonious cell cycle. In addition, cell growth requires efficient systems to clean up erroneous metabolites and macromolecules that would otherwise accumulate in the cytoplasm and ultimately arrest growth. Abnormal proteins are a frequent and cumbersome type of cytoplasmic junk, and ingenious proteolytic systems have evolved to recognize and remove them. Abnormal proteins can arise in various ways: from denaturing treatments, from improper folding of newly synthesized polypeptides (often the case for foreign proteins), and from premature termination of transcription or translation (Gottesman 1996; Miller 1996).

Cytoplasmic proteolysis serves several purposes (Gottesman 1996; Herman and D'Ari 1998). It permits rapid regulatory responses to specific signals, it creates protein turnover in times of starvation, and it removes abnormal proteins. The latter housekeeping role for cytoplasmic

\footnotetext{
${ }^{5}$ Corresponding author. Present address: Department of Stomatology, UCSF Medical Center, San Francisco, California 94143 USA.

E-MAIL Iherman@itsa.ucsf.edu; FAX (415) 476-4204.
}

proteolysis is a major cell need, and inability to perform it quickly perturbs growth.

Regulatory proteolysis is general ly quite specific, each unstable regulator being the preferential substrate of a particular protease, whereas in housekeeping proteolysis, abnormal proteins are often substrates of several proteases (Maurizi et al. 1985). Such lack of specificity is perhaps not surprising, since virtually any protein can become "abnormal" by denaturation, in which case recognition presumably exploits general criteria, shared by most proteases. However, the specific features of proteins that target them for degradation remain largel y unknown.

In a systematic search for protease recognition signals in Escherichia coli, Parsell et al. (1990) showed that a stable protein can be destabilized by addition of nonpolar carboxy-terminal pentapeptide tags. A natural tagging mechanism of this sort was described recently in E. coli, by which a nonpolar amino acid tail is added to peptides translated from truncated mRN A mol ecules (Keiler et al. 1996), making nonpolar tails an important signal in housekeeping proteolysis. Carboxy-terminal nonpolar tags do not cause protein unfolding (Parsell et al. 1990), so they are presumably recognized directly by proteolytic systems. The periplasmic protease Tsp (or Prc) spe- 
Tail-specific degradation of HflB in E. coli

cifically recognizes these tagged polypeptides both in vitro and, for periplasmic proteins, in vivo (Keiler and Sauer 1996), but of course it does not degrade tagged cytoplasmic proteins in vivo (Si lber and Sauer 1994). The proteases responsible for their degradation, which have not been identified previously, are the subject of this report.

We examined the ability of the HflB- and CIpP-dependent proteases to degrade $\mathrm{Cl}$ repressor variants with nonpolar carboxy-terminal tails. HflB is the only essential protease in E. coli. It is a membrane-anchored protein with its active site in the cytoplasm (Tomoyasu et al. 1993) and is responsible for degradation of the the heat shock sigma factor $\sigma^{32}$ and of the regulatory proteins cll and Clll of phage $\lambda$ (Herman et al. 1995; Tomoyasu et al. 1995; Herman et al. 1997; Shotland et al . 1997); few other substrates are known (Kihara et al. 1995). CIpP is the proteolytic subunit of two different cytoplasmic proteases, CIpXP and CIpAP, each of which has distinct recognition signals. For example, CIpXP degrades the $\sigma$ factor involved in the stationary phase, whereas CIpAP degrades the chromosomal addiction module MazE (Aizenman et al. 1996; Schweder et al. 1996).

In the present work, we study four carboxy-terminally tagged proteins. The amino-terminal domain of phage $\lambda$ $\mathrm{cl}$ repressor, normally a stable cytoplasmic protein, is rapidly degraded when tagged with either a nonpolar pentapeptide tail or the SsrA natural 11-amino-acid carboxy-terminal tag (Parsell et al. 1990; Keiler et al. 1996). We show that these tagged proteins are substrates of $\mathrm{HflB}$ - and, in some cases, al so of CIpP-dependent proteases, strongly suggesting that HfIB- and CIpP-dependent proteases can select substrates by their carboxy-terminal tails.

\section{Results}

Tail-specific cytoplasmic degradation in the hflB1(Ts) mutant

We first examined the role of $\mathrm{HfIB}$ in the degradation of three unstable cl variants carrying nonpolar pentapeptide tails-Cl104, cl105, and cl108 (Parsell et al. 1990)and the $\mathrm{Cl}$ variant carrying the natural nonpolar tail, $\mathrm{Cl}-$ SsrA; the stable variant cl 102 served as control (see Table 1). To determine whether $\mathrm{HflB}$ is responsible for the cytoplasmic degradation of these unstable $\mathrm{cl}$ variants, we carried out pulse chase experiments at $42^{\circ} \mathrm{C}$ in a ther-

Table 1. Carboxy-terminal amino acid sequence of the $\mathrm{cl}$ variants

\begin{tabular}{lc}
\hline $\mathrm{cl}$ variant & Carboxyl terminus \\
\hline $\mathrm{Cl} 102$ & -Arg-Ser-Glu-Tyr-Glu \\
$\mathrm{Cl} 104$ & -Ile-His-Trp-Va-Thr \\
$\mathrm{cl} 105$ & -Trp-Val-Ala-Ala-Ala \\
$\mathrm{cl} 108$ & -Ser-Leu-Leu-Trp-Ser \\
$\mathrm{Cl}-\mathrm{SsrA}$ & -Ala-Ala-Asn-Asp-Glu-Asn-Tyr-Ala-Leu-Ala-Ala \\
\hline
\end{tabular}

(Boldface type) N onpolar amino acids; (underline) uncharged polar amino acids; (others) acidic and basic amino acids.

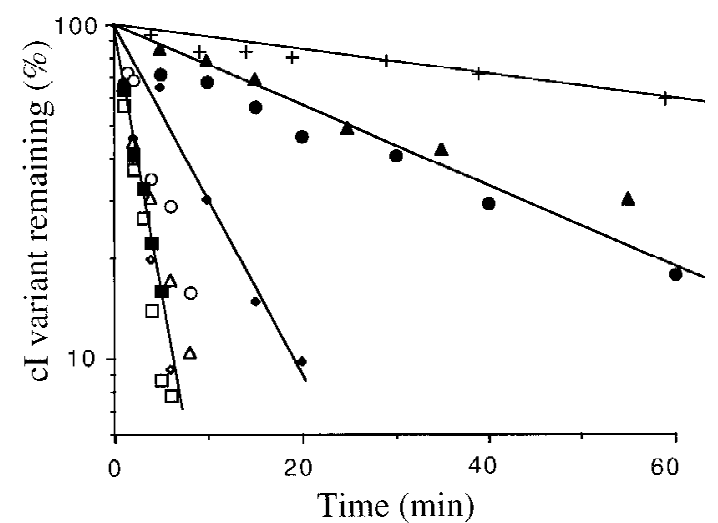

Figure 1. Stability of $\mathrm{cl}$ variants in the hflB1(Ts) mutant. The strains used were JM 105 (WT) or its hflB1(Ts) derivative carrying one of the following plasmids: pDP102 (cl 102), p104 (cl 104), p105 (cl 105), p108 (cl108), or p $\lambda \mathrm{N}$-SPT (cl-SsrA). (+) Wild-type,

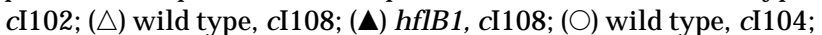
$(\bullet)$ hflB1, cl104; ( $\diamond)$ wild type, cl105; ( $\bullet$ hflB1, cl05; ( $\square$ ) wild

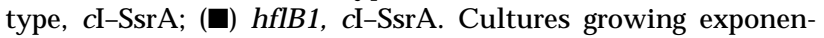
tially at $30^{\circ} \mathrm{C}$ in $\mathrm{M} 63$ supplemented with glycerol and ampicillin were shifted to $42^{\circ} \mathrm{C}$, induced, pulse label ed, and chased, and the amount of labeled cl variant was measured periodically, as described in Materials and M ethods.

mosensitive hflB1(Ts) mutant carrying a plasmid coding for one or another $\mathrm{Cl}$ variant. In wild-type cells at $42^{\circ} \mathrm{C}$, the half-life of all four unstable variants was $\sim 2$ min, whereas the stable control, $\mathrm{Cl} 102$, had a half-life of 200 min (Fig. 1). In the hflB1(Ts) mutant at $42^{\circ} \mathrm{C}$ (Fig. 1), two variants, $\mathrm{Cl} 104$ and $\mathrm{cl} 108$, were strongly stabilized (30min half-lives), one variant, cl105, was partially stabilized (7-min half-life), and Cl-SsrA was not stabilized at all (2-min half-life). These data show that HflB is involved in the degradation of carboxy-terminal-tagged cl104, cl108, and, to a lesser extent, cl105.

Tail-specific cytoplasmic degradation after HflB depletion

Previous experiments have indicated that the HfIB1 mutant protein still has degradative activity toward some of its specific substrates at $42^{\circ} \mathrm{C}$ (Herman et al. 1997), which could explain the continued instability of $\mathrm{Cl} 105$ and $\mathrm{Cl}$-SsrA in the mutant. Therefore, we examined the stability of these $\mathrm{Cl}$ variants in a different conditional system in which the $\mathrm{HflB}$ protein is depleted. The $\mathrm{HflB}$ depl etion strain carries a plasmid-borne copy of hflB under control of the tightly regulated arabinose promoter and a del etion of the chromosomal hflB gene. Cells growing in glycerol plus arabinose at $37^{\circ} \mathrm{C}$ were transferred to glucose medium lacking arabinose to shut off hflB expression. After $6 \mathrm{hr}$ in glucose, the half-lives of induced $\mathrm{Cl} 108, \mathrm{Cl} 105$, and $\mathrm{Cl}-\mathrm{SsrA}$ were $45 \mathrm{~min}, 18 \mathrm{~min}$, and 16 $\mathrm{min}$, respectively, compared to $6 \mathrm{~min}$ in glycerol plus arabinose medium (Fig. 2). These data again show that $\mathrm{HflB}$ is involved in the degradation of $\mathrm{Cl} 108$ and $\mathrm{Cl} 105$ and show further that it is al so involved in Cl-SsrA degradation. However, the fact that $\mathrm{Cl} 105$ and $\mathrm{Cl}-\mathrm{Ssr} \mathrm{A}$ are 


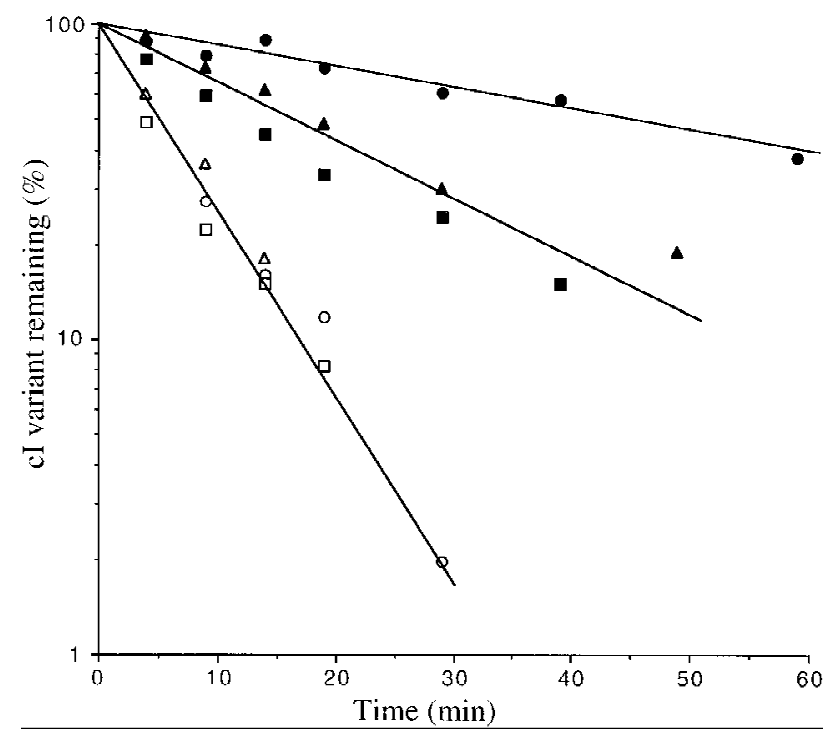

Figure 2. Stability of $\mathrm{Cl}$ variants in the $\Delta$ hflB3::kan mutant. The strains used were JM 105 (WT) or its $\Delta$ hflB derivative, carrying two plasmids, pBHB1 (paraBAD-hflB) and p108 (cl108),

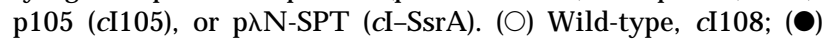

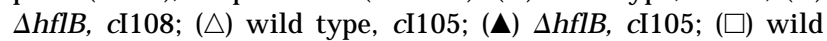
type, cl-ssrA; ( $\mathbf{\square}) \Delta \mathrm{hflb}, \mathrm{Cl}-\mathrm{SsrA}$. Cultures were grown to exponential phase at $37^{\circ} \mathrm{C}$ in M 63 supplemented with glycerol, arabinose, ampicillin, and chloramphenicol. HflB protein was depleted by $6 \mathrm{hr}$ incubation in glucose medium lacking arabinose, after which the cultures were pulse label ed and chased and the amount of labeled cl variant was measured periodically, as described in Materials and M ethods.

only partially stabilized suggests that these proteins are recognized by another protease as well.

Role of CIpP in tail-specific cytoplasmic degradation

We tested the effect of a clpP mutation (which eliminates the CIpXP and CIPAP proteases) in combination with the hflB1(Ts) mutation on $\mathrm{Cl} 105$ and $\mathrm{Cl}-\mathrm{SsrA}$ degradation. Both $\mathrm{Cl}$ variants were strikingly stabilized in the $\mathrm{hfIB1}(\mathrm{Ts}) \mathrm{ClpP}:: \mathrm{Tn} 9$ double mutant at $42^{\circ} \mathrm{C}$, with half-lives of 31 and 120 min for $\mathrm{Cl} 105$ and Cl-SsrA, respectively, compared to $\sim 2 \mathrm{~min}$ in wild type (Fig. 3). Strains mutant for each protease separately exhibited less stabilization than that observed in the double mutant. In the single mutants, the $\mathrm{Cl} 105$ protein (Fig. 3A) was slightly stabilized in clpP::Tn9 (3 min) and in hflB1(Ts) (6 min), and the Cl-SsrA protein (Fig. 3B) was partially stabilized in clpP::Tn9 (9 min) but not at all in hflB1(Ts) (2 min).

These data show clearly that the degradation of $\mathrm{Cl} 105$ and $\mathrm{Cl}$-SsrA involves both $\mathrm{ClpP}$ and HflB. Stabilization of Cl-SsrA in a clpP mutant has al so been observed by Gottesman et al. (1998), who further showed that a related molecule (with a small insert between the $\mathrm{cl}$ and SsrA moieties) can be degraded in vitro by both CIpXP and CIpAP. It is interesting to note that $\mathrm{Cl} 105$ is not totally stabilized in the hflB1(Ts) clpP::Tn9 double mu- tant, suggesting that yet a third protease may be involved in its degradation.

Overexpression of $\mathrm{HflB}$ compensates for the proteolysis defect of the clpP mutant

As shown above, $\mathrm{Cl}-\mathrm{Ssr} \mathrm{A}$ is recognized by the CIpP-dependent proteases and hflB protease. To investigate their respective roles, we measured the half-life of $\mathrm{Cl}$-SsrA in the clpP::Tn9 mutant at $37^{\circ} \mathrm{C}$ so that we could compare it to that in HflB-depleted cells. In ClpP::Tn9 cells there was a 5 -fold increase in stability (30 vs. 6 min in wild type), compared to the 2.5-fold increase in HflB-depleted cells (16 vs. 6 min in wild type). We have previously shown that the $\mathrm{HflB}$ concentration is a limiting factor in the degradation of its substrates $\sigma^{32}$ and $\lambda$ clll (Herman et al. 1995, 1997). We therefore asked whether overproduction of $\mathrm{HflB}$ could overcome the proteolytic defect of the clpP::Tn9 mutant. We introduced into the clpP::Tn9 strain a plasmid in which the expression of hflB is under control of plac. In the resulting strain, the addition of

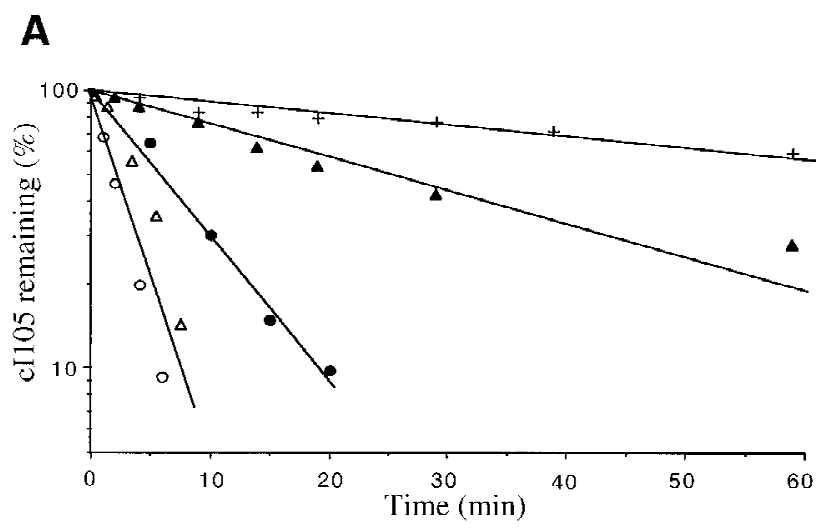

B

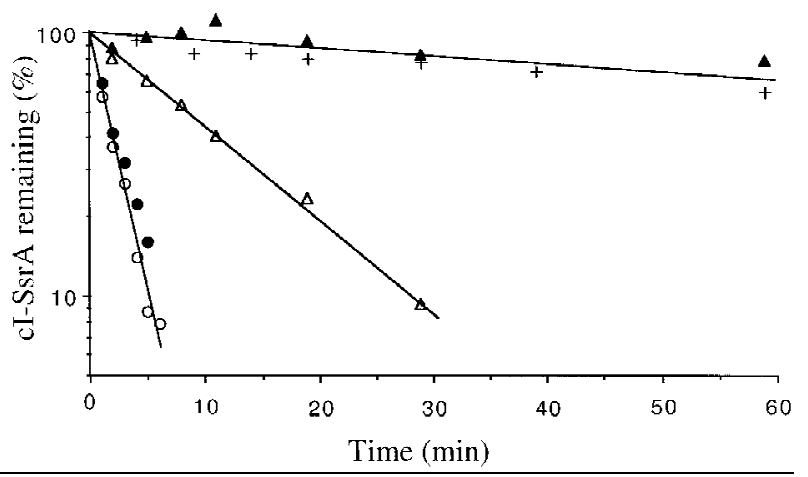

Figure 3. Degradation of $\mathrm{Cl} 105$ and $\mathrm{Cl}-\mathrm{SsrA}$ by both $\mathrm{HflB}$ and Clp. The strains used were JM $105(\mathrm{WT})(O)$, its hflB1 derivative $(\bullet)$, its clpP::Tn9 derivative $(\triangle)$, and its hflB1 clpP::Tn9 derivative ( $\mathbf{\Delta}$ ). (A) These strains carry plasmid p105 (Cl105); (B) they carry plasmid p $\lambda \mathrm{N}$-SPT (Cl-SsrA); a wild-type control (+) carrying plasmid pDP102 (cl102), coding for a stable $\mathrm{cl}$ variant, is shown in A and B. Cultures were grown, pulse labeled, chased, and analyzed as in the experiments shown in Fig. 1. 
IPTG causes overexpression of both HfIB and Cl-SsrA. Under these conditions, the half-life of Cl-SsrA was reduced to $7 \mathrm{~min}$, compared to $28 \mathrm{~min}$ in the clpP::T n9 control strain in which HflB was not overproduced (Fig. 4). The half-lives reported here are longer than those shown in Fig. 3 because of the lower temperature (see below).

These data show that excess $\mathrm{HflB}$ is abl e to replace the $\mathrm{CIpP}$-dependent proteolytic pathway for Cl-SsrA degradation. If the role of $\mathrm{HflB}$ is direct, the results suggest that $\mathrm{HflB}$ can fully recognize the SsrA tag and that the concentration of SsrA-specific proteases determines the half-life of SsrA-tagged proteins.

\section{In vitro degradation of $\mathrm{Cl} 108$ and $\mathrm{Cl}$-SsrA}

To determine whether the action of $\mathrm{HfIB}$ on unstable variants is direct, we purified $\mathrm{HflB}-\mathrm{His}_{6}-\mathrm{M} \mathrm{yc}$ from the membrane fractions of an overproducing strain (Kihara et al. 1996). The purification steps included a nickel column followed by a monoQ column. $\mathrm{His}_{6}-\mathrm{Cl} 108, \mathrm{His}_{6}-\mathrm{Cl}-$ SsrA, and $\mathrm{His}_{6}-\mathrm{Cl} 102$ were purified in a single step, using a nickel affinity column; the preparations were free of ATP-dependent proteases since addition of ATP to the purified $\mathrm{Cl}$ derivatives did not stimulate their degradation.

With these preparations, we investigated the ability of $\mathrm{HflB}$ to degrade tail-tagged $\lambda \mathrm{cl}$ repressor molecules in vitro. As shown in Figure $5 \mathrm{~A}$, purified $\mathrm{HflB}$ degraded Cl108 in the presence of ATP or CTP, under proteaselimiting conditions (the molar ratio of $\mathrm{HflB}$ to $\mathrm{Cl} 108$ was

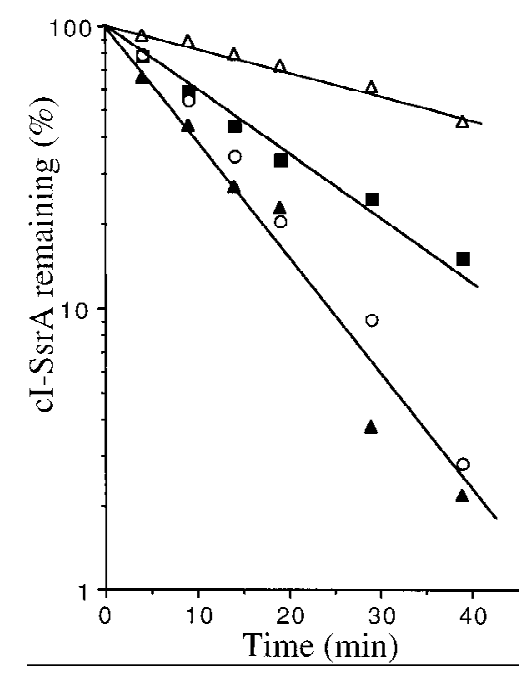

Figure 4. Excess $\mathrm{HflB}$ compensates for loss of $\mathrm{ClpP}$ in the degradation of cl-SsrA. The strains used were JM $105(\bigcirc)$, its $\Delta$ hflB3::kan derivative ( $\mathbf{\square})$, and its ClpP::Tn9 derivative carrying either the HflB-overproducing plasmid pULB6234 (A) or the control plasmid pRK7813 $(\triangle)$. All strains carried plasmid $p \lambda N$ $\mathrm{SPT}$, coding for Cl-SsrA. Cultures were grown to exponential phase at $37^{\circ} \mathrm{C}$ in $\mathrm{M} 63$ supplemented with glycerol, ampicillin, and chloramphenicol. The cultures were pulse labeled and chased and the amount of labeled $\mathrm{cl}$ variant was measured periodically, as described in M aterials and M ethods.
A

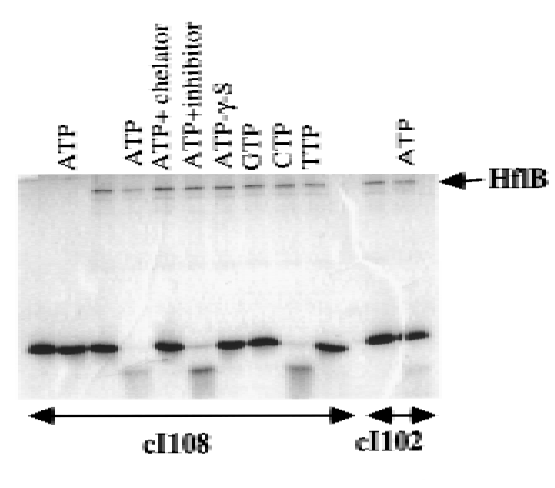

B

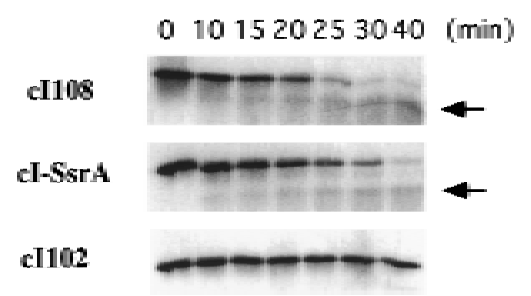

Figure 5. Degradation of $\mathrm{Cl}-\mathrm{SsrA}$ and $\mathrm{Cl} 108$ by $\mathrm{HflB}$ in vitro. His-tagged HflB, Cl-SsrA, Cl108, and $\mathrm{cl} 102$ proteins were purified as described in Materials and M ethods. (A) The indicated reactants were mixed in $\mathrm{P}$ buffer for $30 \mathrm{~min}$ at $37^{\circ} \mathrm{C}$, and the reaction mixture was electrophoresed. Lanes 1-10 contained the unstable variant $\mathrm{Cl} 108$; Ianes 11 and 12 contained the stable variant $\mathrm{Cl} 102$; $\mathrm{HflB}$ was present everywhere except in the controls shown in lanes 1 and 2 . The other reactants in the different lanes were (lane 1) none; (lane 2) ATP; (lane 3) none; (lane 4) ATP; (lane 5) ATP + 1-10 phenanthrolin; (lane 6) ATP + pefabloc; (lane 7) ATP- $\gamma$-S; (lane 8) GTP; (lane 9) CTP; (lane 10)TTP; (lane 11) none; and (lane 12) ATP. (B) Kinetic analysis of reaction mixtures containing $\mathrm{HflB}, \mathrm{ATP}$ and $\mathrm{Cl}-\mathrm{SsrA}$, $\mathrm{Cl} 108$, or $\mathrm{Cl} 102$. A rrow indicate a major breakdown peptide appearing in the first two mixtures. Concentrations of the various reactants are indicated in Materials and M ethods.

1:45). A major product of degradation, about half the protein (5 kD), was visible, suggesting that $\mathrm{HflB}$ acts as an endoprotease. In contrast, the stable variant $\mathrm{cl} 102$ was not degraded under the same conditions, in agreement with the in vivo results and suggesting that $\mathrm{HflB}$ is specific for cl molecules with a nonpolar tail, such as cl108. No degradation was observed when ATP was replaced with GTP or TTP. The degradation is HflB-dependent since addition of a zinc chelator inhibited the reaction whereas a serine protease inhibitor did not. The nonhydrolyzable ATP analog ATP- $\gamma$-S did not allow cl108 degradation, suggesting that this proteolysis requires ATP hydrolysis and thus is energy dependent. Finally, we compared the kinetics of degradation of cl108 and ClSsrA; with a 45 -fold molar excess of substrate at $37^{\circ} \mathrm{C}$, the in vitro half-life of $\mathrm{Cl} 108$ was $10 \mathrm{~min}$, whereas that of Cl-SsrA was 15 min (Fig. 5B).

These results confirm that the unstable $\mathrm{cl}$ variants with nonpolar tails are substrates of the protease $\mathrm{HflB}$, 
suggesting that the nonpolar tail is directly recognized by HfIB.

\section{Temperature dependence of HflB degradation}

In the course of the above work, we noticed that the half-lives of the different cl variants varied with the temperature. To characterize this phenomemon quantitatively, we measured the half-life of $\mathrm{cl} 108$ in vivo as a function of temperature. As shown in Figure 6 , the halflife of $\mathrm{Cl} 108$ was $\sim 20 \mathrm{~min}$ at $30^{\circ} \mathrm{C}$ and $34^{\circ} \mathrm{C}, 6 \mathrm{~min}$ at $37^{\circ} \mathrm{C}, 3 \mathrm{~min}$ at $40^{\circ} \mathrm{C}$ and, as already shown, $2 \mathrm{~min}$ at $42^{\circ} \mathrm{C}$.

These data demonstrate that proteolysis of cl108 increases with temperature. The effect is larger than the known heat-shock induction of the protease $\mathrm{HflB}$ (Herman et al. 1995); this could reflect temperature-dependent changes in substrate conformation or in H flB activity.

\section{Discussion}

Removing abnormal proteins from the cytoplasm is a vital housekeeping function (Miller 1996). In bacteria, mRNA is highly unstable; thus, truncated messenger molecules may be a significant source of such abnormal proteins. In E. coli, peptides arising from such mRNA molecules have recently been shown to be tagged by a process in which the stable 10Sa RNA encoded by ssrA is used to add an 11-amino-acid carboxy-terminal sequence with a nonpolar tail and rel ease them from the ribosome;

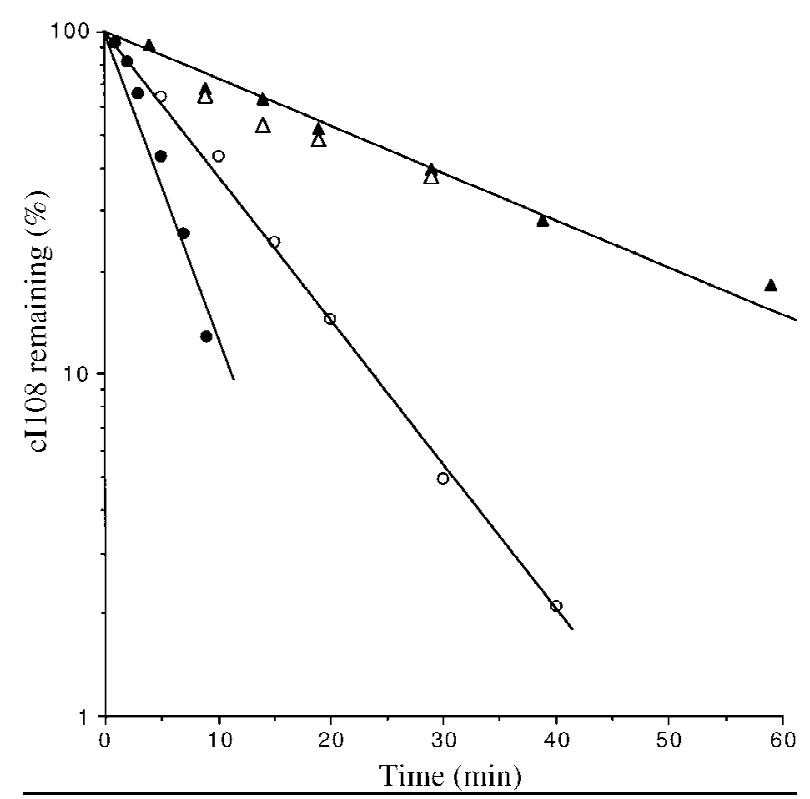

Figure 6. Temperature dependence of cl108 degradation. Strain JM 105 carrying plasmid p108, coding for $\mathrm{cl} 108$, was grown to exponential phase at the indicated temperatures $[(\triangle)$ $30^{\circ} \mathrm{C}$; ( $\left.\mathbf{\Delta}\right) 34^{\circ} \mathrm{C}$; $(\bigcirc) 37^{\circ} \mathrm{C}$; $(\bullet) 40^{\circ} \mathrm{C}$ ] in $\mathrm{M} 63$ supplemented with glycerol and ampicillin, then pulse labeled and chased at that temperature and analyzed as in the experiments shown in Fig. 1. these SsrA-tagged truncated peptides are targeted for degradation (Keiler et al . 1996), and conservation of the nonpolar tail suggests that this system is common to all bacteria (Williams and Bartel 1996). In a systematic screen for protease recognition signals, it was found that proteins could be destabilized by the addition of similar nonpolar pentapeptide tails without changing their thermal stability (Parsell et al. 1990). The periplasmic protease Tsp (or Prc) recognizes proteins with nonpolar tails in vitro and in vivo as well for periplasmic proteins (Silber et al. 1992; Keiler and Sauer 1996). We show here that cytoplasmic proteins destabilized by such carboxy-terminal tags become substrates of the ATP-dependent protease $\mathrm{HfIB}$, an essential, membrane-anchored zinc protease. In some cases the CIpP-dependent proteases are al so involved in their degradation. Using purified $\mathrm{HflB}$ in vitro, the half-life of proteins tagged with nonpolar tails, in the presence of excess substrate was similar to the in vivo half-life, strongly suggesting that the carboxy-terminal nonpolar sequence is recognized by the protease itself.

All cytoplasmic proteases seem to be polyvalent, with both regulatory and housekeeping functions. Proteolysis involved in regulation is often specific, for example, the heat shock specific sigma factor $\sigma^{32}$ is degraded primarily by the protease HfIB (Herman et al. 1995), whereas the stationary phase sigma factor $\sigma^{\mathrm{S}}$ is degraded primarily by CIpXP (Schweder et al. 1996). Housekeeping proteolysis, on the contrary, does not usually exhibit such sharp specificity, and abnormal proteins are often substrates of several proteases. For example, puromycin-truncated proteins are degraded in E. coli by both Lon and HslUV (Maurizi et al. 1985; Straus et al. 1988; Missiakas et al. 1996). The tagged carboxy-terminal cl variants provide an experimental approach to study how proteases can have both specific regulatory functions and nonspecific housekeeping functions. Two of the $\mathrm{Cl}$ variants studied here are degraded exclusively by $\mathrm{HflB}$. Two others exhibit little specificity; they are substrates of $\mathrm{HflB}, \mathrm{Tsp}$, and CIpP-dependent proteases (see Fig. 7). Since these variants differ only in their carboxyl terminus, the information in this small tail would seem to be sufficient to confer specificity to a single or several proteases. It is interesting to note that universal tags ( $\mathrm{cl} 105, \mathrm{cl}-\mathrm{SsrA}$ ) are composed of only nonpolar amino acids (usually buried insi de the protein), whereas specific tags are composed of polar and nonpolar amino acids (see Table 1). Using artificial tail-tagged cl variants, it should be possible to define the mol ecular mechanism by which proteases recognize both regulatory and housekeeping substrates.

Among the proteases able to degrade Cl-SsrA in the cytoplasmic compartment, the CIpXP and CIpAP proteases are collectively more important than $\mathrm{HflB}$, as we observed greater stabilization by loss of CIpP (5-fold) than by loss of hflB (2.5-fold). The importance of CIpPdependent proteases in $\mathrm{Cl}-\mathrm{Ssr} A$ degradation has al so been established by Gottesman et al. (1998). Since HflB is in the membrane, its paramount role may be to degrade abnormal membrane proteins, SsrA-tagged or not, that have their carboxyl termini in the cytoplasm (Fig. 7). 


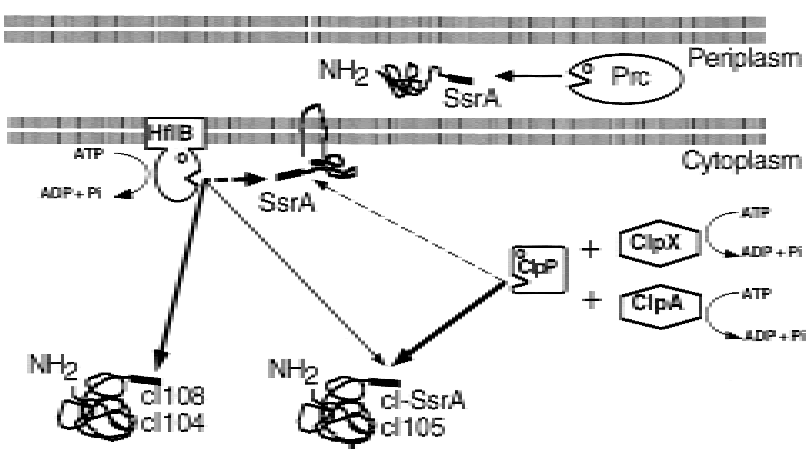

Figure 7. Proteolysis of carboxy-terminal-tagged proteins in E. coli. The degradation of carboxy-terminal-tagged polypeptides is schematized. The three cytoplasmic proteases, all ATP-dependent, are connected to their substrates by arrows. Thicker arrows indicate higher affinity; broken arrows indicate hypothetical reactions.

This idea is consistent with the fact that HflB plays a further role in membrane quality control by degrading uncomplexed membrane proteins (Kihara et al. 1995). The SsrA tag is thus a signal for protease recognition in all cell compartments-the periplasm (Tsp), the membrane $(\mathrm{HflB})$, and the cytoplasm (CIpXP, CIpAP, and $\mathrm{HflB}$, permitting the rapid elimination of tagged proteins, wherever they may be, as one would expect for a housekeeping function.

$\mathrm{HfIB}, \mathrm{CIpXP}$, and CIpAP all carry out tail-specific cytoplasmic proteolysis, and all can degrade SsrA-tagged substrates in vitro (this work; Gottesman et al. 1998). These proteases recognize nonpolar tails, which presumably provide an anchoring site to which they bind. It has recently been shown that CIpX interacts with the SsrA tail through a PDZ-like domain (Levchenko et al. 1997). PDZ domains, defined in eukaryotes, are modules of $\sim 90$ residues that directly bind the carboxy-terminal ends of targeted proteins (Saras and Heldin 1996). Sequence analysis of $\mathrm{HflB}$ reveals homol ogy with the PDZ-like domain of CIp in its well conserved "AAA" module (data not shown). The latter, a 220-250-amino-acid sequence, including an ATPase motif, defines a large family of $>200$ proteins (e.g., regulatory subunits of the $26 \mathrm{~S}$ proteasome) (Confal onieri and Duguet 1995; Beyer 1997).

$\mathrm{HflB}, \mathrm{ClpXP}$, and ClpAP are tail-specific proteases. $\mathrm{HslU}$, which belongs to the Clp family, al so possesses a putative tail-specific binding domain (Levchenko et al. 1997). The Lon protease, too, seems to bind to tails ( $\mathrm{Hi}-$ gashitani et al. 1997; Sen and Rothfield 1998). Tail-specific recognition thus seems to be quite general among $E$. coli cytoplasmic proteases. The resemblance of $\mathrm{HflB}$ to a proteasome regulatory subunit suggests that tail-specific recognition may occur in higher organisms as well, and indeed it has been reported in several eukaryotic systems. For example, the $S 4$ proteasome subunit in human cells binds to the carboxy-terminal part of the papillomavirus oncoprotein E7, apparently as part of a mechanism by which E7 delivers the retinoblastoma tumor suppressor protein to the proteasome (Berezutskaya and
Bagchi 1997). Similarly, mammal ian ornithine decarboxylase, normally degraded by the $26 \mathrm{~S}$ proteasome (Murakami et al. 1992), was stabilized when the 37 carboxyterminal residues were removed (Ghoda et al. 1989), and the degradation of mouse thymidine kinase al so depends on its carboxy-terminal resi dues (Sutterluety et al. 1996). Tail-specific recognition may be a major entry into proteolytic pathways in all organisms.

\section{Materials and methods}

Bacterial strains

The strains used in this work are all E. coli K12 derivatives. There are isogenic strains derived from JM 105, which carries a lacl $^{q}$ allele causing Lac repressor overproduction (Sambrook et al. 1989). $\mathrm{HflB}-\mathrm{His}_{6}-\mathrm{myc}$ was purified from strain AK1181 (Kihara et al. 1996).

P1 vir-mediated transduction was carried out as described by Miller (1992). Plasmid preparations, transformation, cloning, and ligation were carried out as described by Sambrook et al. (1989). The $\Delta$ hflB3::kan ( $\Delta \mathrm{ftsH} 3:: \mathrm{kan}$ ) allele (Akiyama and Shirai 1994) was introduced by transduction to kanamycin resistance in the presence of $70 \mu \mathrm{m}$ L-arabinose into strains carrying plasmid pBHB1. Other protease mutations were introduced by PI transduction, sel ecting for an associated antibiotic resistance marker: hflB1(Ts) zgj-203::Tn10, tetracycline resistance, from strain SL93 (Herman et al. 1993), and cl pP::T n9, chloramphenicol resistance, from strain SL246 (Herman et al. 1995).

\section{Plasmids}

Plasmids pDP102, p104, p105, p108 (Parsell et al. 1990), and p $\lambda$ N-SPT (Keiler et al. 1996) carry the different cl variant genes under control of the IPTG-inducible tac promoter of an ampicillin-resistant pBR322 derivative.

Plasmid pHis-cl108 codes for the $\mathrm{cl} 108$ protein fused to a histidine tag at its amino terminus; it was constructed by amplifying plasmid pcl 108 with primers CIN H2 (5'-GGCGGATCCATGAGCACAAAAAAGAAACC-3') and CICOOHHIII (5'GCCAAGCTTGCAATTTAACTGTGATAAACT-3'). The resulting product was cut with $\mathrm{BamHI}$ and $\mathrm{HindlII}$ and ligated to the PQE8 (Qiagen) BamHI-HindlII backbone fragment. The expected structure of the construct was verified by DN A sequencing.

Plasmids pHis-cl102 and pHis-cl-SsrA overexpress the histine-tagged $\mathrm{cl} 102$ and $\mathrm{cl}-\mathrm{SsrA}$, respectively. To construct these plasmids, we replaced the $\mathrm{N}$ sil-Ndel fragment of pHis-cl108 with the short Nsil-N del fragment of pDP102 or p $\lambda \mathrm{N}$-SPT. The proteolytic susceptibility of each His-tagged variant was tested by pulse chase in a wild-type strain and shown to be identical to that of the untagged variant.

Plasmid pULB6234 (Herman et al. 1993) carries the intact hflB gene cloned downstream of the lac promoter in a low copy number, tetracycline-resistant plasmid vector, pRK7813 (Jones and Gutterson 1987).

Plasmid pBHB1 (Herman et al. 1997) carries the intact hflB gene cloned downstream of the ara promoter in a low copy number, chloramphenicol-resistant pACYC184 derivative, pBAD 33 (Guzman et al. 1995).

Plasmid pSTD113 (Kihara et al. 1996) carries the hflB-his ${ }_{6}^{-}$ myc gene fusion under control of the IPTG-inducible lac promoter of an ampicillin-resistant pBR322 derivative. 


\section{Culture conditions}

Cells were grown in M 63 supplemented with $0.4 \%$ glycerol and $1 \mu \mathrm{g} / \mathrm{ml}$ thiamine or in LB broth (Miller 1992). For HflB depletion, cells were grown in M 63 glucose $(0.4 \%)$ plus 19 amino acids (lacking methionine) at $100 \mu \mathrm{g} / \mathrm{ml}$ each. When necessary, antibiotics were added at the following concentrations: $50 \mu \mathrm{g} /$ $\mathrm{ml}$ ampicillin, $15 \mu \mathrm{g} / \mathrm{ml}$ chloramphenicol; $40 \mu \mathrm{g} / \mathrm{ml}$ kanamycin; and $10 \mu \mathrm{g} / \mathrm{ml}$ tetracycline.

\section{Measurement of $\mathrm{cl}$ variant stability}

All strains carried a lacl ${ }^{q}$ al lel e and a plasmid with the cl variant gene under control of the tac (IPTG-inducible) promoter. The protocol was essentially that described by Parsell et al. (1990). Cells were grown to exponential phase at $30^{\circ} \mathrm{C}$ in glycerol minimal medium supplemented with antibiotics, then shifted to $42^{\circ} \mathrm{C}$ ( $\mathrm{t}=36 \mathrm{~min}$ ), induced with $1 \mathrm{~mm}$ IPTG ( $\left.\mathrm{t}=16 \mathrm{~min}\right)$, pulselabeled $(\mathrm{t}=1 \mathrm{~min})$ with $\left[{ }^{35} \mathrm{~S}\right]$ methionine $+\left[{ }^{35} \mathrm{~S}\right]$ cysteine $(38.3$ $\mathrm{TBq} / \mathrm{mmole}, 0.22 \mathrm{MBq} / \mathrm{ml}$, ICN Biomedical s), and chased ( $\mathrm{t}=0$ ) with $100 \mu \mathrm{g} / \mathrm{ml}$ each cold methionine plus cysteine. For pulsechase experiments done at $37^{\circ} \mathrm{C}$, cells were also pregrown at $37^{\circ} \mathrm{C}$. Samples were electrophoresed on $15 \%$ SDS-polyacrylamide Tris-tricine gels. Radioactivity in the $\mathrm{Cl}$ variant band was reveal ed with a M olecular Dynamics Phosphorlmager and quantified with the ImageQuant 1.33 program (Molecular Dynamics). Half-lives were determined as the slope of the least squares best fit through the points plotted on a semilog graph. All experiments were repeated two to four times; there were no significant variations in the results.

\section{Protein purification}

Purification of $\mathrm{HflB}_{-} \mathrm{his}_{6}-\mathrm{myc}$ was essentially as described by Kihara et al. (1996), with the following modifications. Cells of AK 1272 carrying pSTD 113 were grown at $37^{\circ} \mathrm{C}$ to midexponential phase in $1 \mathrm{~L}$ of TB with ampicillin ( $50 \mathrm{mg} / \mathrm{liter}$ ). IPTG (final concentration $1 \mathrm{~mm}$ ) was added $3 \mathrm{hr}$ before cells were harvested by centrifugation. The DEAE-Sepharose fast flow column was replace by a monoQ fast flow column.

The $\mathrm{His}_{6}-\mathrm{Cl} 102, \mathrm{His}_{6}-\mathrm{Cl} 108$, and $\mathrm{His}_{6}-\mathrm{Cl}-\mathrm{Ssr} A$ proteins were purified by denaturing nickel NTA chromatography according to the Qiagen protocol.

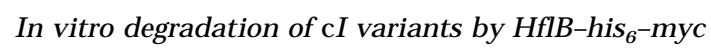

Purified $\mathrm{Cl}$ variant preparations $(30 \mu \mathrm{M})$ were incubated with $\mathrm{HflB}(0.67 \mu \mathrm{m})$ in buffer $\mathrm{P}(50 \mathrm{~mm}$ Tris- $\mathrm{HCl}$ at $\mathrm{pH} 7.6,5 \mathrm{~mm}$ $\mathrm{M} \mathrm{gCl}_{2}, 25 \mu \mathrm{m}$ zinc acetate, $1 \mathrm{~mm}$ DTT, $0.1 \%$ N P-40). The mixture was incubated at $37^{\circ} \mathrm{C}$ and stopped with $2 \times$ SDS sample buffer (Sambrook et al. 1989). ATP, CTP, GTP, TTP, and ATP$\gamma$-S were added at a final concentration of $5 \mathrm{~mm}$. When indicated, pefabloc or 1-10 phenanthrolin was added at a final concentration of $10 \mathrm{~mm}$. Samples were electrophoresed on 15\% sodium SDS-polyacrylamide Tris-glycine gels and revealed by Coomassie stain. Gels were digitalized with an Apple scanner.

\section{Acknowledgments}

We are indebted to Patrick Waller, Akio Kihara, and Yoshinori A kiyama for sending plasmids and strains and to Susan Gottesman for communicating results prior to publication. We thank Danièle Josel eau-Petit, Sarah A des, Lynn Connolly, members of Graham Walker's laboratory, Robert Sauer, and Carol Gross for helpful discussions and warm support. C.H. is Chargé de Recherche of the Fonds $\mathrm{N}$ ational dela Recherche Scientifique (Bel- gium) and received a Bel gian American Educational Foundation award for his stay at MIT. This work was supported in part by grant 6696 from the Association pour la Recherche sur le Cancer to R.D., grant "Contrôle des interactions protéine-protéine dans les réponses cellulaires et les cycles viraux" from the CNRS to P.B., grants GM 28988 and CA21695 from the U.S. Public Heal th Service to G.C.W., and grant 36278 from the National Institutes of Health Service Grants to Carol A. Gross.

The publication costs of this article were defrayed in part by payment of page charges. This article must therefore be hereby marked "advertisement" in accordance with 18 USC section 1734 solely to indicate this fact.

\section{References}

Aizenman, E., H. Engel berg-Kulka, and G. Glaser. 1996. An Escherichia coli chromosomal "addiction module" regulated by 3',5'-bipyrophosphate: A model for programmed bacterial cell death. Proc. Natl. Acad. Sci. 93: 6059-6063.

A kiyama, Y. and Y. Shirai. 1994. Involvement of FtsH in protein assembly into and through the membrane. II. Dominant mutations affecting FtsH functions. J. Biol. Chem. 269: 52255229.

Berezutskaya, E. and S. Bagchi. 1997. The human papillomavirus E7 oncoprotein functionally interacts with the S4 subunit of the 26 S proteasome. J. Biol. Chem. 272: 3013530140.

Beyer, A. 1997. Sequence analysis of the AAA protein family. Prot. Sci. 6: 2043-2058.

Confalonieri, R. and M. Duguet. 1995. A 200 amino acidATPase module in search for a basic function. BioEssays 17: 639-650.

Ghoda, L., T. van Daalen Wetters, M. Macrae, D. Ascherman, and P. Coffino. 1989. Prevention of rapid intracellular degradation of ODC by a carboxyl-terminal truncation. Science 243: 1493-1495.

Gottesman, S. 1996. Proteases and their targets in Escherichia coli. Annu. Rev. Genet. 30: 465-506.

Gottesman, S., E. Roche, Y.-N . Zhou, and R.T. Sauer. 1998. The CIpXP and CIpAP proteases degrade proteins with carboxyterminal peptide tails added by the SsrA tagging system. Genes \& Dev. (this issue).

Guzman, L.-M., D. Belin, M.J. Carson, and J. Beckwith. 1995. Tight regulation, modulation and high-level expression by vectors containing the arabinose $\mathrm{p}_{\mathrm{BAD}}$ promoter. J. Bacteriol. 177: 4121-4130.

Herman, C. and R. D'A ri. 1998. Proteolysis and chaperones: The destruction/reconstruction dilemma. Curr. Opin. Micriobiol. 1: 204-209.

Herman, C., T. Ogura, T. Tomoyasu, S. Hiraga, Y. Akiyama, K. Ito, R. Thomas, R. D'Ari, and P. Bouloc. 1993. Cell growth and $\lambda$ phage development controlled by the same essential Escherichia coli gene, ftsH/hflB. Proc. Natl. Acad. Sci. 90: 10861-10865.

Herman, C., D. Thévenet, R. DAri, and P. Bouloc. 1995. Degradation of $\sigma^{32}$, the heat shock regulator in Escherichia coli, is governed by HflB. Proc. Natl. Acad. Sci. 92: 3516-3520.

Herman, C., D. Thévenet, R. DAri, and P. Bouloc. 1997. The $\mathrm{HflB}$ protease of Escherichia coli degrades its inhibitor $\lambda \mathrm{clll}$. J. Bacteriol. 179: 358-363.

Higashitani, A., Y. Ishii, Y. Kato, and K. Koriuchi. 1997. Functional dissection of a cell-division inhibitor, SulA, of Escherichia coli and its negative regulation by Lon. Mol. Gen. Genet. 254: 351-357.

Jones, J.D.G. and N. Gutterson. 1987. An efficient mobilisable 
cosmid vector pRK 7813, and its use in rapid method for marker exchange in Pseudomonas fluorescens strain HV37a. Gene 61: 299-306.

Keiler, K.C. and R.T. Sauer. 1996. Sequence determinants of C-terminal substrate recognition by the Tsp protease. J. Biol. Chem. 271: 2589-2593.

Keiler, K.C., P.R.H. Waller, and R.T. Sauer. 1996. Role of a peptide tagging system in degradation of proteins synthesized from damaged messenger RN A. Science 271: 990-993.

Kihara, A., Y. Akiyama, and K. Ito. 1995. FtsH is required for proteolytic elimination of uncomplexed forms of SecY, an essential protein translocase subunit. Proc. Natl. Acad. Sci. 92: 4532-4536.

- - 1996. A protease complex in the Escherichia coli plasma membrane: HfIKC ( $\mathrm{HflA}$ ) forms a complex with FtsH (HflB), regulating its proteolytic activity against SecY. EMBO J. 15: 6122-6131.

Levchenko, I., C.K. Smith, N.P. Walsh, R.T. Sauer, and T.A. Baker. 1997. PDZ-like domains mediate binding specificity in the Clp/Hspl00 family of chaperones and protease regulatory subunits. Cell 91: 939-947.

Maurizi, M.R., P. Trisler, and S. Gottesman. 1985. Insertional mutagenesis of the Ion gene in Escherichia coli: Ion is dispensable. J. Bacteriol. 164: 1124-1135.

Miller, C.G. 1996. Protein degradation and proteolytic modification. In Escherichia coli and Salmonella. Cellular and molecular biology (ed. F.C. N eidhardt, R. Curtiss III, J.L. Ingraham, E.C.C. Lin, K.B. Low, B. M agasanik, W.S. Reznikoff, M. Riley, M. Schaechter, and H.E. Umbarger), pp. 938-954. ASM Press, Washington, D.C.

Miller, J.H. 1992. A short course in bacterial genetics. Cold Spring Harbor Laboratory Press, Cold Spring Harbor, NY.

Missiakas, D., F. Schwager, J.M. Betton, C. Georgopoulos, and S. Raina. 1996. Identification and characterization of HsIV HsIU (ClpQ CIpY) proteins involved in overall proteolysis of misfolded proteins in Escherichia coli. EMBO J. 15: 68996909.

Murakami, Y., S. M atsufuji, T. Kameji, S. Hayashi, K. Igarashi, T. Tamura, K. Tanaka, and A. Ichihara. 1992. Ornithine decarboxylase is degraded by the $26 \mathrm{~S}$ proteasome without ubiquitination. Nature 360: 597-599.

Parsell, D.A., K.R. Silber, and R.T. Sauer. 1990. Carboxy-terminal determinants of intracellular protein degradation. Genes \& Dev. 4: 277-286.

Sambrook, J., E.F. Fritsch, and T. Maniatis. 1989. Molecular cloning: A laboratory manual. Cold Spring Harbor Laboratory Press, Cold Spring Harbor, NY.

Saras, J. and C.-H. Heldin. 1996. PDZ domains bind carboxyterminal sequences of target proteins. Trends Biochem. Sci. 21: $455-458$.

Schweder, T., K.-H. Lee, O. Lomovskaya, and A. Matin. 1996. Regulation of Escherichia coli starvation sigma factor $\left(\sigma^{\mathrm{S}}\right)$ by CIpXP protease. J. Bacteriol. 178: 470-476.

Sen, M. and L.I. Rothfield. 1998. Stability of the Escherichia coli division inhibitor protein $\mathrm{M}$ inC requires determinants in the carboxy-terminal region of the protein. J. Bacteriol. 180: 175-177.

Shotland, Y., S. Koby, D. Teff, N. Mansur, D.A. Oren, K. Tatematsu, T. Tomoyasu, M. Kessel, B. Bukau, T. Ogura, and A.B. Oppenheim. 1997. Proteolysis of the phage lambda $\mathrm{CIl}$ regulatory protein by $\mathrm{FtsH}(\mathrm{HflB})$ of Escherichia coli. Mol. Microbiol. 24: 1303-1310.

Silber, K.R., K.C. Keiler, and R.T. Sauer. 1992. Tsp: A tail-specific protease that selectively degrades proteins with nonpoIar C termini. Proc. Natl. Acad. Sci. 89: 295-299.

Silber, K.R. and R.T. Sauer. 1994. Deletion of the prc (tsp) gene provides evidence for additional tail-specific proteolytic activity in Escherichia coli K-12. Mol. \& Gen. Genet. 242: 237240.

Straus, D.B., W.A. Walter, and C.A. Gross. 1988. Escherichia coli heat shock gene mutants are defective in proteolysis. Genes \& Dev. 2: 1851-1858.

Sutterluety, H., S. Bartl, J. Karlseder, E. Wintersberger, and C. Seiser. 1996. Carboxy-terminal residues of mouse thymidine kinase are essential for rapid degradation in quiescent cells. J. Mol. Biol. 259: 383-392.

Tomoyasu, T., K. Yamanaka, K. M urata, T. Suzaki, P. Bouloc, A. Kato, H. Niki, S. Hiraga, and T. Ogura. 1993. Topology and subcellular localization of FtsH protein in Escherichia coli. J. Bacteriol. 175: 1352-1357.

Tomoyasu, T., J. Gamer, B. Bukau, M. Kanemory, H. M ori, A.J. Rutman, A.B. Oppenheim, T. Yura, K. Yamanaka, H. Niki, S. Hiraga, and T. Ogura. 1995. A membrane-bound, ATP-dependent protease $\mathrm{FtsH}$ degrades the heat-shock transcription factor $\sigma^{32}$ in Escherichia coli. EMBO J. 14: 2551-2560.

Williams, K.P. and D.P. Bartel. 1996. Phylogenetic analysis of tmRN A secondary structure. RNA 2: 1306-1310. 


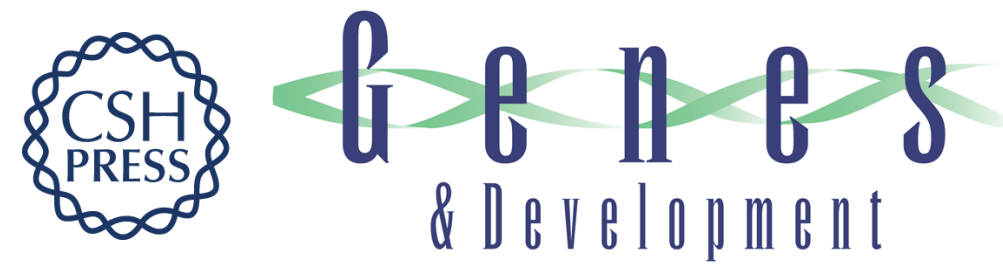

\section{Degradation of carboxy-terminal-tagged cytoplasmic proteins by the Escherichia coli protease HfIB (FtsH)}

Christophe Herman, Danielle Thévenet, Philippe Bouloc, et al.

Genes Dev. 1998, 12:

References This article cites 34 articles, 19 of which can be accessed free at:

http://genesdev.cshlp.org/content/12/9/1348.full.html\#ref-list-1

License

Email Alerting

Receive free email alerts when new articles cite this article - sign up in the box at the top

Service

right corner of the article or click here.

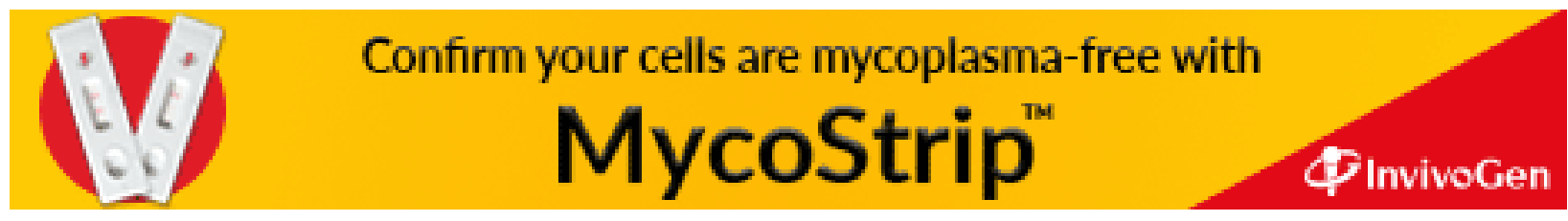

